University of Wollongong

Research Online

Faculty of Informatics - Papers (Archive)

Faculty of Engineering and Information

Sciences

22-4-2008

\title{
The RFID-enabled dairy farm: towards total farm management
}

Adam Trevarthen

University of Wollongong, ATrevarthen@hotmail.com

Katina Michael

University of Wollongong, katina@uow.edu.au

Follow this and additional works at: https://ro.uow.edu.au/infopapers

Part of the Physical Sciences and Mathematics Commons

\section{Recommended Citation}

Trevarthen, Adam and Michael, Katina: The RFID-enabled dairy farm: towards total farm management 2008.

https://ro.uow.edu.au/infopapers/587

Research Online is the open access institutional repository for the University of Wollongong. For further information contact the UOW Library: research-pubs@uow.edu.au 


\title{
The RFID-enabled dairy farm: towards total farm management
}

\author{
Abstract \\ Radio-frequency identification (RFID) is currently being deployed in government mandated livestock \\ identification schemes across the world. RFID in its basic function can help authorities identify animals, \\ especially when traceability becomes paramount during disease outbreaks across regions. This paper \\ provides a view of how an RFID-enabled dairy farm can leverage mobile network infrastructure towards \\ achieving total farm management. The data for the study was collected from two case studies, both NLIS \\ (national livestock identification system) compliant dairy farms on the South Coast of New South Wales \\ in Australia. The Cochrane and Strong Farms were used as models to illustrate the core and auxiliary \\ technology components of an RFID-enabled dairy farm. This paper provides the first end-to-end view of \\ the infrastructure and processes required to achieve an advanced RFID-enabled state-of-the-art dairy \\ farm.
}

\section{Keywords}

RFID, Electronic Monitoring, Farm Management, Traceability, Dairy, Livestock, NLIS, Tag, Transponder

Disciplines

Physical Sciences and Mathematics

\section{Publication Details}

Trevarthen, A. \& Michael, K. (2008). The RFID-enabled dairy farm: towards total farm management. International Conference on Mobile Business (pp. 241-250). Spain: IEEE Computer Society. 


\title{
The RFID-Enabled Dairy Farm: Towards Total Farm Management
}

\author{
Adam Trevarthen and Katina Michael \\ School of Information Systems and Technology, University of Wollongong \\ ATrevarthen@hotmail.com,katina@uow.edu.au
}

\begin{abstract}
Radio-frequency identification (RFID) is currently being deployed in government mandated livestock identification schemes across the world. RFID in its basic function can help authorities identify animals, especially when traceability becomes paramount during disease outbreaks across regions. This paper provides a view of how an RFID-enabled dairy farm can leverage mobile network infrastructure towards achieving total farm management. The data for the study was collected from two case studies, both NLIS (national livestock identification system) compliant dairy farms on the South Coast of New South Wales in Australia. The Cochrane and Strong Farms were used as models to illustrate the core and auxiliary technology components of an RFID-enabled dairy farm. This paper provides the first end-to-end view of the infrastructure and processes required to achieve an advanced RFID-enabled state-of-the-art dairy farm.
\end{abstract}

\section{Introduction}

An abundance of literature is available regarding the technology of electronic identification, in the form of RFID [1]. However, there is a gap regarding electronic animal identification for the purposes of improving total farm management practices, especially on dairy farms. Articles by Ishmael [2] and Karnjanatwe [3] provide a glimpse of the possibilities for utilizing electronic identification for enhanced farm management, however these articles are not focused upon the dairy farm industry, nor do they provide an indepth look at the total farm management operations used at these farms. Ishmael [2] tells of the economic benefits achieved by a group of farmers resulting from the utilization of RFID technology to provide individual identification and subsequently enhanced farm management operations on their beef farm in America. Karnjanatwe [3] provides an insight into an actual application of RFID technologies used to enable enhanced farm management of pigs, such as automating the feeding process and regulating how much each pig eats. James [4] and Davies [5] provide more information on deriving benefits specifically related to the dairy industry, however also lack depth and explanations of the farm management practices undertaken to gain these benefits. James states how electronic identification can be used to reduce the labor required for the milking process, providing large cost savings, while Davies [5]demonstrates the ability to improve the quality of milk yields through controlled feeding processes based on electronic identification.

\section{Australian dairy farm case studies}

There were two in depth Australian case studies conducted for this investigation [6]. Case Study A was conducted on the Mandelyn Holsteins dairy, owned and operated by the Strong family. This farm was selected as the traditional (low RFID implementation) case study, as they have a well established, highly reputable dairy, however do not currently utilize any RFID devices in their farm management operations. As such, this dairy provides a prime example of how dairy farms can operate currently without the aid of RFID devices. Case Study B can be considered advanced and was undertaken on the Cochrane dairy farm, located in Pyree on the NSW South Coast [7]. This farm has been selected as the advanced case study, as it has a strong use of RFID technology, and is well known in the region as one of the most advanced RFID setups. As the farm also utilizes RFID tags that are compliant with Australia's NLIS (National Livestock Identification System) system, the farm provides a currently applicable example of how participants in this system can derive additional benefits through the use of RFID on their dairy farms. The data collection techniques used in this study included interviews, observations and document analysis.

\section{Mandatory components for RFID- enabled dairy farms}




\subsection{RFID tags and boluses}

RFID tags, boluses or microchips form the basis of any dairy farm RFID system. The choice of which RFID device a farm utilizes is specifically a matter of personal preference for the farm owners. Each of these devices provides the same functionality, reliability and accuracy, and is intended to last for the lifetime of the cow. Further to this, each device has its own advantages and disadvantages (such as tags being cheaper, boluses being irretrievable until the time of slaughter etc.), leaving the eventual choice of device to the individual farmer. There are a number of tags, boluses and microchips available from various vendors, however there are currently only three tags, and one bolus that have been approved for use with Australia's NLIS [8]. As such, Australian farms that are required to participate in the NLIS by state law, or who wish to participate voluntarily, should adopt one of these NLIS recommended devices [9]. Microchips cannot currently be utilized by those participants in the NLIS, as none have been approved to date.

The chosen RFID device should be attached to the cow immediately after birth (or several days thereafter). This ensures that all cows on a farm are tagged, and allows the RFID tags to be utilized for farm management practices immediately. Even if RFID devices are not utilized until later stages of a cow's life, attaching these devices at birth ensures that the tagging has been conducted for all cows, and removes the need for any special RFID attaching sessions at later dates (thus causing an unnecessary change in routine and possible stress for a cow).

\subsection{Herd management software}

The ability to digitally store herd information is a valuable tool for all farms, and a necessity for those desiring to utilize RFID to aid in farm management. Herd management software provides mechanisms for farmers to store individual cow data into a database. Data can be entered into this software application manually via an easy to use, standardized interface, or alternatively, data can be automatically entered through the use of other digital devices (such as milk meters, cow weight scales) linked to this database. Automating data entry through the use of other digital devices enables data to be stored reliably and accurately, while reducing the labor requirements of the farmers by saving them from entering the data themselves.

Many capabilities of herd management software are virtually impossible to achieve utilizing traditional paper-based techniques. For example, utilizing such an application allows a farmer to easily view, analyze, manipulate and sort data, all in a matter of keystrokes.
Such an activity would be extremely time consuming at the least, if not completely impossible for farmers to complete via traditional, paper-based techniques. Subsequently, farmers are able to easily and immediately view information on individual cattle, view an entire cow's history (calving date, artificial insemination dates, treatments etc.), produce reports on individual cows, selected cows or the herd as a whole etc. All this can be conducted without physically looking at hand-written or previously printed documents. Additionally, the data, and results from any analysis/reports can then be viewed via a digital display or in hard copy documents. Such information storage and manipulation capabilities provide farmers with an extremely valuable resource to aid them in their farm management activities and decisions. Such herd management software also provides RFID devices with the information required to make a decision or conduct an action. The Cochrane dairy case study provided a valuable demonstration of how herd management software is utilized in this fashion. For example, the information stored regarding each cows last recorded volume of milk production and their stage of lactation provides the basis for the automated decision of how much feed to be provided to each cow during the milking session.

Australian dairy farmers may also receive additional benefits by utilizing herd management software that provides the capability to communicate automatically with the NLIS central database. Utilizing this approach, in the event of a farmer recording the receipt of cattle from another farm, or the movement of cattle from one of their farms to another, the software can then prepare and send the required information update files to the NLIS central database via the Internet. Thus, purchasing herd management software with this in-built capability further aids to reduce labor, while also saving farmers who may not be highly experienced with computers and technology from having to learn how to send these NLIS updates themselves. Cattle software vendors such as HerdLink currently provide software with this capability [10].

\subsection{Fixed RFID reader}

In order to derive any use and subsequent benefit from the practice of identifying every cow with RFID tags, a farm requires an RFID reader device. Subsequently, at every position in which a farmer wishes to utilize a cows RFID number on a regular basis, a fixed RFID reader should be utilized. These provide a reliable and robust source of identification, while also providing a greater range for reading RFID devices than portable RFID readers. These fixed 
readers can be used in conjunction with other devices to enable a subsequent action or series of actions to be performed, or decisions to be automatically made. For example, fixed readers may be utilized for the purposes of identifying a cow as she enters the milking parlor, and subsequently recording the time and date of this read to the central herd management database (indicating the milking time for this cow). Likewise, fixed RFID readers may be utilized to record a cows milk production (in association with milk meters), to identify cows required for drafting gate operations etc. To facilitate such actions, a communication (network) link is required to the herd management software.

At the simplest level of RFID implementation, a fixed RFID reader should be placed upon entry to the dairy, and have a network link to the herd management software. This is the most fundamental placement of a fixed RFID reader on dairy farms, as lactating cows must pass through this reader at least twice a day on their way to be milked. At a minimum, placing the RFID reader in this position allows data to be automatically recorded regarding the time and date that each cow enters the milking parlor, and should at least be arranged so as to display cow information at the end of the dairy. Placing the reader in this position also provides the possibility for the reader to serve as the basis for a wide range of optional operations to be conducted within the dairy that require individual identification of cows (e.g. automatic feeding etc).

\subsection{Digital device network - wireless/wired}

A form of digital network is required so as to enable the communication of devices between one another, with RFID readers and the central herd management software. There are essentially three methods of establishing such a network - wired, wireless or hybrid. Each has their own advantages and disadvantages, and the eventual selection of the implementation type will depend upon the characteristics and preferences of individual dairy farms.

A completely wired network involves connecting all devices with a network cable, with no ability to cater for wireless connections or wireless devices. Utilizing this network, all devices will have a direct connection to the herd management database, thus providing access to the latest information, and providing the capability to immediately write information to this database. Such a network is best suited for farms where all devices requiring network communication abilities are permanently fixed in a location (e.g. milking controller unit, fixed RFID reader on entry to dairy etc).
A wired network arrangement is likely to be cheaper than establishing a wireless network on the farm in terms of up-front costs. However, ongoing costs for this network may be higher due to maintenance that is likely to be required for the cables used to operate the network. Additionally, these cables may suffer reliability problems due to unforeseen circumstances, such as rodents eating away at exposed cables in or near the dairy, general wear and tear on the cables. If communication through a cable in this network type is affected, it could cause a malfunction, or halt the operation of a device (such as a milk meter, or feeding control units), or even force the entire network to become inoperable (for example if a basic ring topology is used).

Ideally, farmers will be utilizing wireless networks in future arrangements. This will enable an array of devices, whether fixed or portable, to be linked directly to real-time data in the herd management database. Such devices include the mainstream computer network devices, such as PDAs (Personal Digital Assistants), laptops, desktop personal computers and printers, however will also provide the vital links to dairy farm devices, such as RFID readers, milking controller units, feed management units, drafting gates, and a vast array of other devices that could be configured to operate under computer control, or require access to herd information for operation.

Providing this direct link from these devices to the herd management database enables all devices to refer to the latest herd information for their operation. Likewise, a wireless network also provides these devices with the ability to record changes, updates or new information immediately to the herd management database. Additionally, new devices are also quite easy to introduce to a wireless network, as no cable extensions are required to be linked to them.

Alternatively to a completely wired or wireless network, a hybrid of the two can be formed. This involves some components of the network utilizing direct wired connections to the herd management software and server application, while other devices are provided with portable abilities, however do not have a direct link to the herd management database or to any other device on the network at these times. This may be the preferred option where there are devices that are intended to be permanently placed in a position, while other devices require portability, however do not need immediate read and write access to the herd management database. Utilizing the hybrid approach, portable devices can be connected to the network and subsequently the central herd management database at regular intervals (e.g. daily), where they can download 
the latest information from the central herd management database. The farmer can then remove these devices from the network, and take this device with them out into the field, where they can use this device to view, record updates or modify existing data. However, any changes made will only be reflected in their local portable version of the database at the time of recording. The farmer must then return to base, and attach the device to the central network again to upload the data they recorded while in the field onto the wired central herd management database (synchronizing data between the two).

Essentially, the decision of wireless, wired or hybrid networks must be considered at each individual farm, based on the requirements and a cost-benefit analysis. It is believed that as wireless technologies advance in the future, providing greater capability and functionality while reducing costs, that wireless network arrangements will become the predominant network type. The network established by the Cochrane's to link their RFID readers to their dairy software (and herd management software), feed dispensers and drafting gates provide a strong example of the use and value that such networks can provide. While this network is currently completely wired, it could also be easily adaptable to support mobile devices (such as PDAs) in a hybrid arrangement, to enable an even greater range of abilities in the future.

\section{Auxiliary components for RFID-enabled dairy farms}

Implementation of the mandatory components will provide farms with the equipment they require to conduct basic RFID operations. If desired, these components can be utilized as the foundation for a much larger RFID operation, designed to provide additional value for farm management practices. This can be achieved through the use of any, or all of the following optional components- the selection of which should be made so as to meet the requirements and aims of individual dairy farms.

\subsection{Portable RFID reader}

Having an RFID reader that is portable provides farmers with the ability to read the RFID number of individual cattle, regardless of the cow's location on the farm. This may enable simple actions to be taken, such as identification of cows in the field.

At a basic level, portable readers are capable of reading the RFID tag of a cow, and displaying the cows RFID number on a small digital screen in-built into the portable reader, and possibly providing an audible reading of the identification number e.g. the Allflex Compact Reader [11].

At a more advanced level, a portable RFID reader could be attached to a personal digital assistant (PDA). Prior to use, the PDA can be loaded with herd management software, and the data stored on the farms central herd management software application can be copied to this PDA - effectively providing a mobile copy of the herd information. Utilizing this arrangement, the farmer can then scan a cows RFID tag with the portable RFID scanner, and the identity and information pertaining to that cow can be provided on the screen of the PDA. The farmer can then use the PDA similar to how they would utilize their host desktop computer, being able to browse the cow's information, and should also be allowed to record and update cow information on-site. For example, a farmer could give a cow a penicillin injection - to record this, they simply scan the RFID tag of the treated cow, then use their PDA to record the details of that injection.

Such data recording and updates may be immediately reflected in the central herd management software if the portable device has a direct network link to it (e.g. wireless network). Alternatively, if a direct link to the software is not possible, the updated information could be retained in the portable device, and uploaded to the herd management database at a later time when the device can gain a direct link to the network (i.e. transfer via network cable). Either way, the farmer will be receiving the benefits of being able to easily and rapidly retrieve and view data in the field, while also enabling simple, accurate and timely data recording. Such an arrangement would also remove the duplication of effort that is currently required on both the Strong and Cochrane farms for recording information to their herd management applications- as farmers would not be required to manually record this data in the field before entering it again into the herd management software at a later time.

\subsection{Weight scales on entry to dairy}

The weight of cows is another significant factor that can be used to determine the overall health of a cow, detect any possible problems that may arise, and aid to identify if there are any nutritional changes that may be required to a cow's diet. Placing a weight scale on the entrance to the dairy will ensure that each cow is weighed at a regular interval, and would not require any changes to a cow's routine to gain this weight data. This weight scale can be associated with a permanent RFID reader, thus enabling each cow to be identified before standing on the scales, and their resulting weight to be recorded in the herd management database. This 
data can then later be viewed and analyzed by the farmer, or alternatively, an advanced arrangement could involve software that is able to recognize and alert farmers of anomalies or concerning variances in weights for each cow. For example, a cow may lose weight when she is not given (or is not eating) enough food to satisfy her energy requirements to continue producing high quantities of milk. However, a loss of body weight may also occur if a cow falls sick, feed intake is restricted etc. [12] Whatever the reason, it is important that farmers are informed of such changes, and thus allowed to investigate and take any required action.

It is proposed that advanced software be developed to work in conjunction with these weight scales. Such advanced software could analyze the cow's current stage of the lactation cycle, age and the amount of feed she is currently receiving and possibly provide a suggested reason for any concerning weight variances detected. For example, a cow may require more feed. These suggestions could then be provided to the farmer at the end of each milking session, allowing them to then inspect the cow and agree or disagree with the recommendation, depending on their own analysis of the cow and her situation.

\subsection{Automated feed-dropping control units}

Feed bins that have the ability to automatically drop a designated amount of feed into the feed trough of each individual cow have been demonstrated to be highly effective in dairy farms. Both case studies use this technology, and consider it an integral component of their herd management activities. However, the Cochrane dairy derive greater use from their feed bins, by actually combining the operation of their feed bins with the RFID tags of their cows and the herd management software. This subsequently enables automated feed calculation and delivery in the dairy.

Automated feed units provide a variety of benefits to farms, including reduced labor, cost savings, removal of possibility for human error, and of course the ability to automatically calculate and provide the required amount of feed for cows to sustain or increase their milk production.

Beyond their current abilities, it is believed that future development of these automated feed bins could provide enhanced benefits for the farmers. Firstly, the use of milk meters to record the amount of milk produced by each cow at every milking session will also enable greater possibilities for extending the capabilities of feed bins. Utilizing such an approach will enable feed amounts to be derived upon the most recent data of cow milk production, thus enabling feed amounts to adapt to meet the changing requirements of each cow.

Utilizing milk meters will also allow an average milk production value to be derived and utilized in calculating the amount of feed to provide for each cow. This average may be taken from the production of the cow during their entire current lactation cycle, or perhaps derived from a selected amount of previous milking sessions (e.g. the average milk provided over the past 10 milking sessions). This ability to refer to an entire cow's production history may also enable herd management software to recognize certain patterns in the production of each cow. Subsequently, feed may be adjusted to meet these patterns (e.g. every 10 days there is a rise in the production of a certain cow, thus provide it more feed than meets its average on this day). Recognizing patterns in milk production, and providing up-to-date production records to serve as the basis for feed amount calculation aids to ensure each cow is provided with the required amount of feed to sustain their current milk production, and also to encourage this production rate to increase - a vital element to maximizing milk production from a herd.

Additionally, it is proposed that not only will feed bins be utilized to vary the ingredients of this feed. These feed bins could mix additional additives to each individual cows basic feed to boost specific elements that the cow has been recorded as requiring. For example, increased fiber, protein etc. The requirements for what additives to be supplied for individual cows should be entered by the farmer (possibly based on veterinary results, milk analysis etc.), and the automatic feed bins can then execute this requirement, mixing in the required additive for a specified amount of milking sessions. This subsequently further aids farmers in managing their farm, providing them with assistance to ensure the development and good health of their cows, while aiding to ensure high milk production of a high quality and volume.

\subsection{Feed troughs with measuring capability}

The capability to provide a specific amount of feed to each cow to meet their requirements is one of the most valuable capabilities for a dairy farm. However, this ability can be undermined if there is no way of telling if a cow is actually eating all of their allocated feed. From the floor of the milking parlor in which the milking operators stand, it is difficult, if not impossible to see if there is any feed left in the feed bails when each batch of cows leaves. As such, a cow may not be eating all (if any) of their allocated feed, however the farmer and the herd management software will not be aware of this unless there is a manual form of checking 
done when every cow leaves their bails. Utilizing weight scales to measure the amount of feed left in each feed trough provides this important feedback capability for the farmer and software to measure any feed left in the feed troughs.

This can be achieved by placing weight scales underneath the feed trough of each bail, and having feed troughs with bases that open (base flaps drop down), allowing any feed remaining in these troughs after each cow has left to be dropped below to the scales. This leftover feed can then be weighed, and the resulting weight recorded in the herd management software, thus providing information on the amount of feed provided, amount leftover, and subsequently the gross amount of feed consumed by each cow.

It is proposed that this measurement process be triggered by the milking operators taking the required action to signify the end of milking. This may be the press of a button (as at the Cochrane's), pull of a rod (as at the Strong's) or other means. So as to save the milking operators from then having to clear the feed from the scales before the next batch of cows enter the milking parlor, it is proposed that containers be used on the top of the scales with the ability to store a large amount of feed. Thus, when the operator takes the required action to open the milking parlor for the next batch of cows (press of a button/pull of a rod etc.), the scales will then re-calibrate themselves to consider their current weight as the starting point ('zero') for the next calculation. Subsequently, when the next batch of cows complete milking, the feed can be dropped into the container atop of the scales again, and the scales perform the required calculation to provide a weight reading for the amount of feed left in each independent bail, i.e., current reading minus the reading taken at the end of previous milking session.

Utilizing this approach will not only allow farmers to ensure that their cows are eating their required amount of feed, but will also aid to detect any cows that may be having a problem, such as illness. It is proposed that the software that stores this consumption data be able to identify any cows with concerning feed intake rates, and subsequently alert farmers to this issue. For example, if a cow is eating less than $70 \%$ of their allotted feed, there may be a need for the farmer to examine this cow and investigate possible reasons why this may be happening. Such low eating could be an early warning sign of sickness, and thus this approach would allow the farmer to separate this cow from the herd and take any required action to being her back to good health. Additionally, a reduced feed intake is also a characteristic of a cow on heat, and thus this may provide further information to support other signs of a cow being on heat [13].

\subsection{Milk meters}

In a business where milk is the primary product, it is important to know how much milk each cow is producing, and likewise, to have a source of feedback to establish what factors enable your cows to produce the maximum amount of milk. Milk meters provide this valuable ability, measuring the amount of milk each cow provides at every milking session.

Milk meters are placed in the milk flow line leading from each set of milking cups to the main milk flow line (leading to the vat). From here, the meter can gauge the amount of milk flowing through the pipes from each cow. To be useful, this information should be automatically recorded in the herd management database, and associated with the cow currently registered by the software as being present in that particular bail number. Other pieces of information, such as the time at which the reading took place, the cows bail number, and duration of milking can also be derived from milk meters, and should be stored in the database. These pieces of information serve as solid records of each cow's milking session, and may provide grounds to various analysis activities for the farmer.

Both the Strong and Cochrane dairies currently utilize the services of Dairy Express herd recording to provide information relating to the production volume of each individual cow. This service also provides information relating to the fat and protein components, somatic cell counts, and other information as requested. While this is all certainly valuable information, the infrequency at which this sampling occurs (monthly) reduces the scope of applications that this information can be used for. For example, this data does not provide a reliable basis on which to conduct day-to-day herd management operations. A great deal of cow characteristics can change over the course of a month, and utilizing such distributed testing, farm operations will not be able to adapt to meet the changing characteristics and subsequent requirements of cows.

Similarly, utilizing data collected only on one day of the month could provide misleading results. For example, a cow may have an unusually bad milking day on the day of herd recording- providing poor quality milk and a low volume of it. Subsequently, she will receive a bad report on her milk, and also have her feed adjusted to suit a low production cow for the rest of the month. However, she may normally be producing a much greater quantity of milk, and at higher quality than what was sampled on the day. Consequently, 
treating her as a low production cow would reduce her ability to maintain or increase her true milk output, and could result in decreased health.

Despite these negative aspects for the use of this information in farm management operations, the results of Dairy Express analysis remain a valuable asset for dairy farms. The information provided by these analyses other than production volume (fat content, protein etc.) provide valuable feedback on the quality of herd milk for the farmer, and are also information products that individual farms are unlikely to be able to practically gain through their own on farm testing facilities. Additionally, Dairy Express provides the ability for the individual results to be accumulated for the various categories of this analysis (thus providing total herd information), and compared to other dairies in the farms particular region, state or indeed the whole of Australia. This provides a great ability to benchmark the performance of your herd in multiple aspects, something that would be much more difficult by any other means. As such, it is not proposed that the implementation of milk meters replace the use of herd recording services, but rather they should be used to supplement this process- providing information relating to milk production volumes that can be more effectively utilized for farm management activities, and unveil a wider range of possible applications for such data.

Both the Cochrane and the Strong dairies stated their desire to implement milk meters in the future, indicating the presence of a firm desire within the dairy industry to adopt these devices. It is believed that the implementation of these devices could become an integral component of dairy farming in the future. As previously alluded to, a great benefit that milk meters provide is the ability for farmers to achieve a complete cycle of information. Currently, farmers are able to control and measure many aspects of a cow's environment and lifestyle. For example, they are able to control the amount of feed provided to each cow, the ingredients and ratio of mixture for feed in the dairy (e.g. grain and wheat mixture), what paddock the cows are placed into (subsequently the type of grass present, fertilizer or other products used in maintaining this paddock etc.), when cows are milked, when they are fed and a variety of other factors. However, without milk meters, farmers are unable to accurately gauge how varying certain elements in a cow's environment may affect their milk production.

Armed with the information collection ability provided by milk meters, farmers are able to experiment with varying elements of certain cow's environments in an attempt to identify the ideal conditions for achieving maximum production with their particular herd. Every farm property is different, and every herd of cows may be considered different. Thus, while many dairy management practices are common between farms, it is important for farmers to fine tune their herd and farm management practices to suit their specific herd and farm, so as to attempt to gain the greatest possible milk production and quality from their cows.

Such experimentation can be achieved by taking a selection of cows, and modifying any of a wide array of elements that make up their environment. These elements should be varied only one at a time (so as to be able to identify what the characteristic is that caused any changes that may be realized), and the milk production of the selected group monitored for any growth or decline. Examples of varying elements may include varying the milking times for the selected group, the quality of feed provided, the amount of feed provided, paddocks placed in (and the grass/characteristics of their paddock compared to others), whether they are given hay or not, additional feeding sessions etc. The results of varying these factors should be analyzed, and any positive aspects implemented with the remainder of the herd.

Utilizing milk meters will also aid to identify any problems that may arise in the herd (such as illness). For example, if a cow provides a significantly lower amount of milk than their usual output, the system will be able to identify this disparity and alert the operators to check this cow when milking has completed. In this way, any illnesses or problems occurring with cows can be identified quickly and easily, subsequently enabling rapid treatment. A further benefit of such a device is the ability to provide audit functionality for the amount of milk produced. Currently, the only record of the amount of milk provided to the manufacturer is via a report provided by the manufacturer after they have collected a vat of milk from the dairy farm. Utilizing milk meters, the farm is able to verify that the amount of milk stated by the manufacturer as having been received is in alignment with the total amount recorded by the milk meters. This will of course aid to ensure that farmers are being paid for the correct volume of milk, while also acting as a mechanism to identify if there may be a leak in the milk transportation pipes in the dairy. As milk is the primary product produced by dairies, this audit capability is an important aspect to ensuring farms are receiving the right income, and also minimizing possible shrinkage (through leaking pipes etc). 


\subsection{Milking controller unit}

Milking controller units are essential pieces of equipment for all modern dairy operations. This is the device that controls the suction and suckling motion of the milking cups attached to the teats of each cow. This unit can function effectively without the use of RFID technology (as demonstrated in the Strong dairy case study), however it is recommended that RFID technology, combined with herd management software be incorporated in all future implementations of milking controller units. Combining these technologies will provide a range of enhanced options and capabilities for the operation of the milking controller unit.

Utilizing this combination of components, it is proposed that future implementations may be able to gain and interpret a cow's complete milking history. Subsequently, the units will then be able to establish for themselves the required manner for milking the cow that has been assigned to their bail. As such, the software would need to have the ability to work with a range of milking controller units, or may be provided by a vendor to work in conjunction with their milking controller units. This ability to automatically select the milking style would remove the need for the operator to do this, thus reducing the demands on operators, while also reducing the possibility for human error in selecting milking styles.

At a more advanced level, it is proposed that display devices be incorporated into the milking controller units, providing a mechanism to display a range of information to the dairy operator relating to the cow currently located in the milking bail. This could include any information stored in the herd management database, however it is felt that the essential information would include whether penicillin has been injected, if milk is required to be withheld for any reason, if a cow has a bad teat (thus this teat is not to be milked), if the cow is a slow milker, if the milk should be used for second grade milk (if farm utilizes such a category of milk) and if the cow has freshly calved. This specific information is critical in determining if and how a cow should be milked differently.

The Cochrane dairy demonstrated that such information can be made available on screens at either end of the dairy, and audible readouts also provided for such information to provide a further alert to operators of a cow requiring additional attention during the milking process. While this setup is quite useful, the information regarding each cow is still not directly available to be viewed at each individual milking station, as would ideally occur. Rather, both the Cochrane and Strong dairies utilize other visual identification mechanisms to recognize particular attributes of individual cows at the point of milking (and also to simply identify cows with particular attributes for general herd management). These identification mechanisms include colored tail tags, colored ankle tags, paint on cow udders etc. The meaning, and number of these identification markings however, differ between the case studies. It is further believed that this sort of variance in identification devices will exist between all dairy farms. Whilst quite effective, these mechanisms are not foolproof. The requirement for milking operators to notice these identifiers, and subsequently take appropriate action (such as disposing of milk unsuitable for production) leaves room for human error in milking. Additionally, these identifiers may inadvertently fall from the cow while in the paddock, be covered by mud during milking sessions or suffer fading (thus being less eyecatching) etc., subsequently making it difficult or impossible for operators to recognize these markings.

If these identifiers are not recognized during milking, the farmer may face quite serious consequences. For example, such occurrences could lead to a cow being milked in an incorrect fashion, such as attempting to milk a teat that has been dried off. Even greater consequences will be realized if milk that should be disposed of (such as that extracted from a cow who has had a recent penicillin injection), accidentally flows through to the main milk vat. This will result in the bad milk contaminating an entire vat of milk. This will subsequently cost the farmer the intended revenue for the entire vat of milk, as it must then all be disposed. Furthermore, if the farmer does not realize that contaminated milk has entered their vat and allow the dairy manufacturer to collect the milk (placing it into their large collection tanker with milk from other farms), the dairy manufacturer will end up detecting this contamination when testing the collection tanker of milk at their own depot. Subsequently, the farmer responsible will then be identified by the manufacturer via testing of individual farm samples taken at the time of pickup. The farmer may then face a fine, or be forced to reimburse the manufacturer for the value of the entire collection tanker of milk that must now be disposed.

For this reason, it is proposed that the milking controller unit, combined with display devices (a form of computer screen) at each milking bail be utilized to aid the milking operator in identifying important requirements for each cows milking. This can be achieved by utilizing RFID readers on the entry to the dairy, combined with bail blockers, and the ability for the herd management software to assign a cow to a 
milking bail as they pass through the RFID reader. The milking controller unit can then be linked with the herd management database, thus providing it with the ability to receive and interpret individual cow data for the milk assigned to its corresponding bail number. This received data can then be displayed to the milking operator via the related bail information display device. It is important to note that such a system should be used to complement the existing visual identification methods on each cow, rather than replace them - thus providing dual identification capabilities for important cow characteristics.

At the most advanced level, this display device would be a small and very well shielded computer screen, displaying each cow's information in an easy to view interface. Information that may affect the milking procedure would be highlighted, and if the information is critical to milking (such as if the milk is to be withheld), the milking controller unit will not allow milking to proceed until it receives a signal to continue from the milking operator. This would act as a check that the milking operator is aware of any special actions that may be required for particular cows, has taken the required action (such as plugging the milk flow lines into a barrel for disposal), and is now ready to begin milking this cow. This 'continue' signal could be achieved by placing a small keypad beside each screen, however, ideally an entire keyboard could be provided at each milking bail (with a bendable plastic mould covering the keys). Having a keyboard would enable a range of feedback to be provided by the milking operator, and also allow for data to be entered into the database regarding each cow. This may include information such as whether any drugs were administered during milking (such as synthetic oxytocin), any problems that arose during milking, additional comments etc. Additionally, a 'watch' button could also be provided as an input device. This button would be pressed by an operator if they notice something about a cow during milking that they would like to investigate after milking. The software will then remind farmers to investigate this cow at the end of milking, and if drafting gates are being utilized at the dairy, then pressing this button will immediately select this cow for drafting as it exits the dairy - thus providing easy access to this cow after milking.

A less expensive version of the above information intensive milking controller system can be established utilizing a panel of lights to transmit information from each milking controller unit. Each light on the panel could be labeled, and illuminated to display any pertinent information for the milking of the cow. For example, four lights could be placed so as to represent the four teats on a cow's udder, and each light would subsequently illuminate to represent a teat that is not to be milked (thus complementing the use of ankle tags as is the practice on the Cochrane farm). The main drawback of this lower cost arrangement is that it is unlikely to allow direct entry of information to the herd management database.

An additional benefit of either of the bail information display device arrangements is that such a system may provide greater flexibility for farmers in employing milking operators. Utilizing either of the previously described systems, milking operators do not need to be extensively trained in what visual identifiers to look for at each farm, as each cows information is clearly provided to them at each bail via a chosen display device. Further, the system can aid to ensure operators have recognized any particular characteristics that would require a varied milking procedure, as it will prevent the milking cups from working until the operator provides the required signal to continue (e.g. pressing 'continue' button) at the specific bail. This may provide farmers with the ability to hire outsiders or contracted milking operators to fill in for regular milking operators in unforeseen circumstances, or to allow the regular farmers to take a holiday.

Milking control unit vendors such as DeLaval currently provide milking controller units with similar capabilities to this. The DeLaval 'MPC' provides information to the milking operator through a series of labeled lights and a small display screen with scrolling text. A keypad is also provided to enable information to be directly updated and entered into the herd management database (DeLaval provide a herd management system entitled 'ALPRO'), and a variety of information can be viewed on the screen of the unit [14]. As such, it is believed that at least part of the proposed milking controller unit arrangement is achievable currently, and the technology involved in these units is likely to further advance in the future.

\subsection{Automatic drafting gates}

The use of drafting gates has been demonstrated at the Cochrane dairy, and has been shown to provide large savings of both time and labor for the farmers in extracting individual cows from the main herd. These cows may be extracted for a wide variety of reasons, including the need for veterinary treatment, artificial insemination etc. Additionally, this automatic drafting ability enables farmers to provide additional attention to selected cows on a regular basis (such as by drafting show cows into a paddock with additional feed). The most useful location for these drafting gates is believed to be on the exit to the dairy, as this is where all 
lactating cows must pass at least twice a day. Operating in conjunction with herd management software, these gates would be a valuable asset to almost any dairy farm.

\subsection{Temperature monitoring}

It is evident from the articles of Higgins [15] and Hostetter [16], that it is possible to incorporate temperature sensing abilities into RFID microchips currently. Such a device will provide the temperature of the cow along with the cow's unique identification number every time the tag is read by an RFID reader.

The temperature of a cow is certainly a valuable attribute for a farmer to utilize in managing their herd. Importantly, fluctuations in the body temperature of a cow can indicate that the cow may be falling ill. Thus, reading this temperature will allow a more rapid response to aid in detection and subsequent treatment of any illnesses that a cow may have attracted. It will also enable the farmer to take action to minimize the spread of the illness by being able to rapidly isolate the cow for observation and treatment. Of course, the quicker an illness can be detected and treated, the less time a cow will spend affected by this illness and hence minimize probable reduction in milk production. As such, rapid treatment of cow illness is in the best interests of a farm financially, as well as to aid to keep the cows in good health.

A rise in temperature may also indicate that a certain cow is entering heat. It is important to know when this occurs, as this presents the farmer with a window of opportunity to artificially inseminate the cow (if they are intending to impregnate the cow). This temperature sensing ability may aid to supplement the current visual manual mechanisms of detecting heat utilized on farms such as the Cochrane's, and also supplement or replace the use of Karmars, as utilized on the Strong farm.

There may also be other reasons for temperature fluctuations among cows, however whatever the reason, it is important that anomalies in temperatures be identified and investigated as soon as possible. As such, when temperature fluctuations are recognized by the system, functionality could be incorporated to allow the system to alert the farmer of such fluctuations via means such as a beeper device that the farmer may carry, sending a text message to their mobile phone, or by similar rapid alert device.

At a basic level, a temperature sensing RFID device could be read by fixed RFID readers at the entry to the dairy. Such an arrangement would ensure that each cow has their temperature read at a regular interval at least twice a day, thus providing valuable information to the farmer. At a more advanced level, it is proposed that
RFID readers also be placed at other high congregation areas throughout the farm. For example, placing a high powered RFID reader near a water trough in a paddock, hay feeders or similar areas that are frequented by cows. Under this approach, more temperature readings can be gathered between milkings, thus providing an enhanced ability to detect temperature variations, and also to view patterns of temperature change among the cows (e.g. middle of the day they may be warmer than at sunrise).

Ultimately, if readers could be utilized to read a multitude of low-powered RFID devices over a large distance, then such readers could be placed in each paddock to interrogate the entire herd's RFID devices at pre-determined intervals. This would provide a far greater picture of temperature fluctuations and patterns among individual cows in the herd.

\subsection{GPS tracking}

The precise details of GPS (Global Positioning System) operation are outside the scope of this research, however it is believed that a device may be developed in future that provides a combination of GPS and RFID technology, subsequently providing enhanced farm management capabilities. It is proposed that GPS technology be included in RFID tags in the future, thus providing the ability to track cattle movements, and locate individual cows with a single program. This will provide a range of abilities and benefits for farmers.

One of the primary benefits of utilizing GPS with RFID tags is the ability to gain the exact location of where a cow is currently located on the farm. This saves the farmer from having to lookup records of where the cow is currently located, or having to visit the paddocks and try to visually identify the cow they are looking for. Obviously, with a small herd size, this is not a particularly prominent issue (as farmers will be able to know cow locations from their own knowledge of the herd and cow movements), however as herd size increases, GPS location ability becomes increasingly valuable. This ability is further enhanced as the farmer may be able to use a PDA or other mobile device to display a map of their farm and pinpoint the cow's location within this farm layout. Utilizing this approach, farmers can be guided to the exact location of any cow they desire.

Further to the primary use of tracking of cattle, a more advanced GPS-RFID setup could provide software that enables farm boundaries to be plotted and associated with the GPS devices. Using this arrangement, the software could detect if a cow (or cows) move beyond these plotted boundaries (i.e. 
escaping from a paddock). When such an occurrence is detected, the software can inform the farmers of this by displaying an alert message to all available display devices (computer monitors, PDAs etc.), and send a further message to designated people via mobile phone text messages, paging devices etc., so as to attempt to raise immediate notification. This will aid to ensure that if cows do escape their paddocks, that rapid action can be taken to precisely locate them, and bring them back to their paddock- thus hopefully reducing the chances of an injury being sustained by the cows while outside their paddocks (such as being hit by a car, eating poison baits, encountering other predatory animals or humans etc.), or the dairy simply losing their cows.

Once the cow has been retrieved and returned to their paddock, farmers can then also use their GPS software to trace back the path the cow took to escape from their paddock, and subsequently take any action they feel may be necessary to prevent the incident from occurring again (e.g. patching a fence, implementing electric fences). Any loss of lactating cows will have an immediate impact upon the milk production of the herd, and thus has direct financial implications for dairy farmers. Similarly, if any injuries are sustained to a cow this may impact their milk production also (permanently or temporarily). As such, it is in farmer's best interests to minimize the risk of such incidents, which a GPS system utilizing plotted boundaries can facilitate. Similarly, the combination of GPS with RFID will aid to prevent and detect any theft of cows. While this is not a particularly serious problem in Australia, it remains a volatile possibility. If a farm is utilizing GPS-RFID devices to track their cows, in combination with software that recognizes farm boundaries, it will be quite apparent to a farmer if their stock is being stolen, as there will be a large and rapid exodus of cows from their property boundaries. Not only will GPS capability aid to detect such an act, but it can then be used to trace the cows if the thieves manage to successfully remove them from a property. Additionally, proof of identification and ownership of each cow can be provided via the RFID capability of such devices.

Furthermore, software could be designed to detect individual cow movement that may be considered out of the ordinary. This may include if a cow does not move as much as it is expected (based upon the historical location chronicle of the cow), or likewise, if it is moving significantly more than expected or usual. If a cow is moving significantly less than usual, this could be a strong sign of illness, and certainly something worthy of a farmer's investigation.
Additionally, this tracking may also be used as a mechanism for detecting when cows are in heat. When a cow is in heat, it is stated that their activity (movement) will increase by up to eight times the normal rate [13]. Thus, if a cow's movement is detected to be abnormally high, this may be a strong sign that she is in heat, and thus notification of this should be provided to the farmer.

\subsection{Automatic calf feeding machine}

Through the demonstration of the use of an automatic calf feeder on the Cochrane dairy farm, it is evident that strong benefits can be gained from the use of this device. Primarily, this includes a dramatic reduction of labor, ensuring that calves are fed the most appropriate amount of milk for their age to encourage and support their growth, and to provide management information for the farmers. These benefits can save farmers both time and money, while also acting as an investment in their cow's futures. As such, it is believed that while this is not a necessary requirement for operating an RFID-enabled dairy farm, the benefits of utilizing this device make it highly recommended, especially for large herds, or simply farms with many calves.

\section{Principal findings}

There are a number of conclusions that can be drawn from this research [17]. The first is that RFID is currently being utilized and development of RFID hardware and software is continuing. Secondly, size does matter, both regarding herd size and the corresponding benefits of using RFID and in terms of economies of scale for the technology. On farms with relatively small herds, farmers are likely to have intimate knowledge of the herd through their own interactions with the animals, and additionally, farm labor is unlikely to be in constant demand. Thus, the abilities of RFID to provide information storage, manipulation and easy retrieval, or dairy automation possibilities are unlikely to add significant value, and thus may be perceived as an unnecessary cost. On the other hand, with large herds, whereby farm labor is virtually on constant demand, and an intimate knowledge of each cow in the herd is difficult or impossible to achieve, RFID technology provides the ability for dramatic benefits to be realized. Thirdly, RFID expands management capability through the information and automation capabilities. This includes the likes of automatic feed dispensing units, automatic calf feeding, automatic drafting etc- all of which can dramatically save labor requirements, provide more reliable and accurate operations, and enables farmers to 
spend more time managing the vast array of other activities involved in operating a dairy farm. Additionally, these automation practices may aid the development, health and overall milk production of cows, thus providing further benefits for the farmer. Fourthly, it is concluded that legal requirements around the world have become a driving force behind the adoption of RFID on dairy farms.

\section{Major implications for dairy industry}

The use of RFID will assist farmers to maximize their productivity - an important aim in the modern competitive dairy industry. It is expected that the new farm management practices enabled by RFID will allow farmers to increase the volume and possibly the quality of milk output from their herd. This may be achieved through improved practices to monitor the health of their herd - thus minimizing illness and subsequent low production of cows, speeding up the milking process - thus enabling the cows to return to the paddocks quicker, optimizing feed to suit each cow production and stage of lactation cycle etc. The use of RFID for automation will also aid to minimize labor inputs, thus allowing each farmer to cater for more cows, or enabling farmers to have more time to spend on other activities - either way, maximizing results from their input.

Considering the potential benefits offered by the implementation of RFID on dairy farms, combined with the global push for RFID to be utilized for livestock tracking, it is believed that the development and adoption of RFID technology on dairy farms will continue for quite some time. This adoption rate may even grow as the benefits of such implementation become more widely recognized, and correspondingly the costs of the technology lower with expected economies of scale. This adoption may continue to the point where the use of RFID becomes a mandatory aspect to survive in the future dairy market. As a consequence of the RFID adoption within the dairy industry, it is likely that farmers will become more involved with ICT (Information and Communication Technology) generally. Traditionally, farmers have had little use for computers, however with the introduction of the NLIS, it is likely that computers will become a central part of farm management. Subsequently, this is expected to raise the level of IT literacy amongst the industry.

The current and predicted continued uptake of RFID technology on dairy farms provides a large opportunity for the involvement of third parties. This may include existing vendors diversifying into this industry, or new enterprises opening and developing products to specifically suit the industry, consultants opening up to provide advice on dairy layouts, how and what devices to implement, third-party distributors and intermediaries etc. Considering that many traditional farmers may not have a great deal of technological experience or are comfortable with radical changes, such third party involvement may be considered more of a requirement than an opportunity. In Australia's case, the state or national government may wish to commit more resources to provide support and information on the technology and its possible uses for the dairy industry, especially considering the mandatory regulation of NLIS current in some states, and soon to spread nationwide. Additionally, it may be possible for labor agencies to provide temporary milking operators for a brief or extended term to aid in operating a dairy farm. On farms with advanced RFID automation systems in the future, there may be little need for operators to have extensive knowledge of a farm or herd to conduct milking, as the machines will prevent them milking cow incorrectly, provide them with each cows information etc. Being able to hire such personnel could provide a temporary employee in the case of unexpected absence of a milking operator, or may enable the usual operators to take time away from the farm.

\section{References}

[1] A. Trevarthen, "The national livestock identification system: the importance of traceability in e-business," Journal of Theoretical and Applied Electronic Commerce Research, vol. 1(1), pp. 49-62, 2007.

[2] W. Ishmael, The power of one, http://beefmag.com/mag/beef_power_one/ 2001.

[3] K. Karnjanatwe, How RFID tags can track livestock [Online]. Bangkok Post. http://www.bangkokpost.com 2005.

[4] D. James, "Automatic cow identification pays in the milking parlor", Farmer's Weekly, p. 42, 2004.

[5] R. Davies, "Electronic gains aplenty, http://www.agricultural-technology.co.uk/fwedit/fwedit.html 1997.

[6] A. Trevarthen, "The importance of utilizing electronic identification for total farm management: a case study of dairy farms on the south coast of NSW", Unpublished Honors Thesis, http://ro.uow.edu.au/thesesinfo/1/ 2005.

[7] A. Trevarthen, and K. Michael, "Beyond mere compliance of RFID regulations by the farming community: a case study of the Cochrane Dairy Farm," in The Sixth International Conference on Mobile Business, Toronto, Canada, pp. 1-8, 2007.

[8] Meat and Livestock Australia, "A guide for producers and lot feeders, http://www.mla.com.au/NR/rdonlyres/ F0AC2D8A-27B4-4633-B823-AC4A6BC91B0D/0/PG_

Version30_Compiled.pdf, p. 18, 2005. 
[9] RFIDAA, "NLIS: Research from Wollongong University about leveraging NLIS requirements", RFID Australian Association, October and November, p. 4, 2006.

[10] HerdLink, "NLIS", http://www.herdlink.com.au/nlis. shtml, 2004.

[11] Allflex Australia, "Allflex compact reader", http://www.allflex.com.au/78.html 2005.

[12] Ontario Ministry of Agriculture, Food and Rural Affairs, "Body Condition Scoring of Dairy Cattle", http://www.omafra.gov.on.ca/english/livestock/dairy/facts/92 -122.htm, 1996.

[13] DeLaval, "Management of the Dairy Cow," http://www.delaval.com/Dairy_Knowledge/EfficientDairyHe rdMgmt/Management_Of_The_Dairy_Cow.htm 2005.

[14] DeLaval, "DeLaval Milking Point Controller MPC", http://www.delaval.com/Products/MilkingEquipment/Autom ation/Loose_housing/Milking_point_controller_MPC/default .htm 2005 .

[15] K. T. Higgins, "Engineering R\&D: Temperature readings by remote control" http://www.foodengineering mag.com/CDA/ArticleInformation/features/BNP_Features_ _Item/0,6330,99353,00.html [Accessed 16/4/2005], 2003.

[16] J. Hostettor, "Animal-tracking chips now let you in on how Fido is feeling", http://www.usatoday.com/tech/news/ techinnovations/2003-04-21-animal-chip_x.htm, 2003.

[17] A. Trevarthen, "Beyond compliance: making NLIS work for you", in Opportunities through adversity... is this the climate for change? The Australian Dairy Conference, Shepparton, Australia, 26 February- 1 March, p. 95, 2007. 